\title{
Molecular detection and identification of tick-borne bacteria and protozoans in goats and wild Siberian roe deer (Capreolus pygargus) from Heilongjiang Province, northeastern China
}

\author{
Haoning Wang ${ }^{1}$, Jifei Yang ${ }^{2 *}$, Muhammad Uzair Mukhtar ${ }^{2}$ Zhijie Liu² ${ }^{2}$ Minghai Zhang ${ }^{1}$ and Xiaolong Wang ${ }^{1,3^{*}}$
}

\begin{abstract}
Background: Small ruminants are important hosts for various tick species and tick-associated organisms, many of which are zoonotic. The aim of the present study was to determine the presence of tick-borne protozoans and bacteria of public health and veterinary significance in goats and wild Siberian roe deer (Capreolus pygargus) from Heilongjiang Province, northeastern China.
\end{abstract}

Methods: The occurrence of piroplasms, Anaplasma phagocytophilum, A. bovis, A. marginale, A. capra, A. ovis, Ehrlichia spp. and spotted fever group rickettsiae was molecularly investigated and analyzed in 134 goats and 9 free ranging $C$. pygargus living in close proximity.

Results: Piroplasm DNA was detected in 16 (11.9\%) goats and 5 C. pygargus. Sequence analysis of 185 rRNA sequences identified 3 Theileria species (T. luwenshuni, T. capreoli and T. cervi). Four Anaplasma species (A. ovis, A. phagocytophilum, A. bovis and A. capra) were identified in goats and C. pygargus. Anaplasma ovis and A. bovis were detected in 11 (8.2\%) and 6 (4.5\%) goats, respectively; A. phagocytophilum, A. bovis and A. capra were found in 3, 7 and 3 C. pygargus, respectively. Sequence analysis of $16 \mathrm{~S}$ rRNA sequences revealed the presence of 5 different genetic variants of A. bovis in goats and C. pygargus, while the analysis of $165 \mathrm{rRNA}$ and gltA sequence data showed that A. capra isolates identified from C. pygargus were closely related to the genotype identified from sheep and Haemaphysalis ginghaiensis, but differed with the genotype from humans. Anaplasma/Theileria mixed infection was observed in 2 (1.5\%) goats and 5 C. pygargus, and co-existence involving potential zoonotic organisms (A. phagocytophilum and A. capra) was found in 2 C. pygargus. All samples were negative for A. marginale, Ehrlichia spp. and SFG rickettsiae.

Conclusions: These findings report the tick-borne pathogens in goats and C. pygargus, and a greater diversity of these pathogens were observed in wild animals. Three Theileria (T. luwenshuni, T. capreoli and T. cervi) and four Anaplasma species (A. ovis, A. phagocytophilum, A. bovis and A. capra) with veterinary and medical significance were identified in small domestic and wild ruminants. The contact between wild and domestic animals may increase the potential risk of spread and transmission of tick-borne diseases.

Keywords: Tick-borne pathogen, Theileria, Anaplasma, Zoonosis, Goats, Siberian roe deer, China

\footnotetext{
*Correspondence: yangjifei@caas.cn; yttuhh@yeah.net

${ }^{1}$ College of Wildlife Resource, Northeast Forestry University,

Harbin 150040, Heilongjiang, People's Republic of China

${ }^{2}$ State Key Laboratory of Veterinary Etiological Biology, Key Laboratory

of Veterinary Parasitology of Gansu Province, Lanzhou Veterinary

Research Institute, Chinese Academy of Agricultural Sciences, Xujiaping 1,

Lanzhou 730046, Gansu, People's Republic of China

Full list of author information is available at the end of the article
}

(c) The Author(s) 2019. This article is distributed under the terms of the Creative Commons Attribution 4.0 International License (http://creativecommons.org/licenses/by/4.0/), which permits unrestricted use, distribution, and reproduction in any medium, provided you give appropriate credit to the original author(s) and the source, provide a link to the Creative Commons license, and indicate if changes were made. The Creative Commons Public Domain Dedication waiver (http://creativecommons.org/ publicdomain/zero/1.0/) applies to the data made available in this article, unless otherwise stated. 


\section{Background}

Small ruminants are known to harbor various ticks that act as vectors and reservoirs of tick-borne pathogens of veterinary and/or medical importance. They play an important role, not only in the life-cycle of ticks, but also in the natural maintenance and transmission of these pathogens [1]. Tick-borne diseases affect domestic and wild ruminants, especially sheep, goats, cattle and deer [2]. In the past two decades, an increasing number of tick-borne pathogens have been identified in domestic animals and a variety of wild cervids, some of which have been confirmed as causes of human infection, such as Anaplasma phagocytophilum, Anaplasma capra, Babesia divergens, Babesia venatorum, Ehrlichia canis, etc. [3-6]. This fact is of great concern in terms of tick-borne disease control, since animals are usually asymptomatic carriers that may serve as reservoirs of the infection.

With advances in molecular techniques, a number of well-known and potential novel tick-borne bacteria and protozoans have been identified in unexpected hosts and geographical locations [7]. In China, Theileria annulata is the causative agent of bovine theileriosis and has been identified in sika deer [8]; Theileria uilenbergi causes ovine theileriosis and has been detected in red deer and sika deer [9]; and Babesia motasi infects sheep and goats and has been reported in sika deer [8]. This information warrants further investigation of tick-borne pathogens in both domestic and wild animals simultaneously. Siberian roe deer (Capreolus pygargus) is a commonly encountered wild animal and distributed mainly in Xinjiang and northeastern China [10]. The aim of this study was to determine the occurrence of the tick-borne bacteria and protozoans in goats and free-ranging C. pygargus from Heilongiiang Province, northeastern China.

\section{Methods}

\section{Study sites and collection of specimens}

In the present study, EDTA-anticoagulated blood samples were collected from 134 asymptomatic goats and 9 free-ranging C. pygargus from September 2017 to August 2018 in forest farms in Hebei Forestry Bureau, Mudanjiang city and Chaihe Forestry Bureau from Heilongjiang Province, northeastern China. The forest farms are local administrative units which have changed their role from timber production to forest and wildlife conservation over the last two decades. They never serve as large scale husbandry units, while backyard livestock breeding by its employees is common. Those domestic animals graze freely and share a common habitat with wild ungulates, which can frequently be found feeding very close to the local settlements. The samples were collected from rescued $C$. pygargus during the course of daily routine patrol by local wildlife disease monitoring stations. The goats were sampled in the herds close to the sites where C. pygargus included in this study were found. Sample collection and animal handling complied with the Animal Ethics Procedures and Guidelines and was approved by the Animal Ethics Committee of Northeast Forestry University. Genomic DNA was extracted from $200 \mu \mathrm{l}$ of whole blood using a QIAamp DNA Mini Kit (Qiagen, Hilden, Germany) according to the instructions of the manufacturer.

\section{PCR reactions}

The extracted DNA was screened for the presence of piroplasms, Anaplasma, Ehrlichia and spotted fever group (SFG) rickettsiae by PCR. The PCR primers and cycling conditions used in this study are listed in Table 1. Briefly, nested PCRs were employed for the detection of piroplasms, A. phagocytophilum, A. bovis, and A. capra based on $18 S$ rRNA, $16 S$ rRNA and gltA genes, respectively. Anaplasma ovis, A. marginale, Ehrlichia spp. and SFG rickettsiae were detected by conventional PCR based on $m s p 4$ gene, $16 \mathrm{~S}$ rRNA and ompA genes, respectively. PCR reactions were conducted in an automatic thermocycler (Bio-Rad, Hercules, CA, USA) in a total volume of $25 \mu \mathrm{l}$, including $2 \mu \mathrm{l}$ of DNA sample as previously described [11]. The DNAs extracted from the whole blood of animals infected with $T$. annulata, A. phagocytophilum, A. bovis, A. marginale and A. ovis, and the DNAs from ticks positive for E. chaffeensis and SFG rickettsiae that had been verified by sequencing, were used as the positive control for corresponding PCR reactions; sterile water was used as the blank control for each run. Amplified fragments were electrophoresed on a $1.0 \%$ agarose gel containing $10 \mu \mathrm{l}$ of GoldView (SolarBio, Beijing, China) and visualized under UV transillumination.

\section{DNA sequencing and phylogenetic analysis}

The DNA fragments were purified with a AxyPrepTM DNA Gel Extraction Kit (Axygen, Union City, CA, USA), cloned into pGEM-T Easy vector (Promega, Madison, WI, USA) and transformed for sequencing using BigDye Terminator Mix (GenScript, Nanjing, China). The nucleotide sequences obtained in this study were compared with previously published sequences deposited in GenBank by a BLASTn search or by using the ClustalW multiple alignment algorithm in the MegAlign program of the Lasergene 7.1 software package (DNAStar, Madison, WI, USA). The phylogenetic trees were inferred by using the neighbor-joining (NJ) method with the Kimura two-parameter model, and the bootstrap test was replicated 1000 times [12]. 
Table 1 Primers and PCR amplification conditions

\begin{tabular}{|c|c|c|c|c|c|c|}
\hline Pathogen & Target gene & Primer name & Primer sequence $\left(5^{\prime}-3^{\prime}\right)$ & $\begin{array}{l}\text { Annealing } \\
T\left({ }^{\circ} \mathrm{C}\right)\end{array}$ & Amplicon size (bp) & References \\
\hline \multirow[t]{4}{*}{ Piroplasm } & $18 \mathrm{~S}$ rRNA & Piro1-S & CTTGACGGTAGGGTATTGGC & 55 & $\sim 1410$ & {$[24,25]$} \\
\hline & & Piro3-AS & CCTTCCTTTAAGTGATAAGGTTCAC & & & \\
\hline & & PIRO-A1 & CGCAAATTACCCAATCCTGACA & 55 & $\sim 430$ & \\
\hline & & PIRO-B & TTAAATACGAATGCCCCCAAC & & & \\
\hline \multirow[t]{4}{*}{ A. phagocytophilum } & $16 \mathrm{~S}$ rRNA & EE1 & CCTGGCTCAGAACGAACGCTGGCGGC & 55 & $\sim 1430$ & {$[26,27]$} \\
\hline & & EE2 & AGTCACTGACCCAACCTTAAATGGCTG & & & \\
\hline & & SSAP2f & GCTGAATGTGGGGATAATTTAT & 60 & 641 & \\
\hline & & SSAP2r & ATGGCTGCTTCCTTTCGGTTA & & & \\
\hline \multirow[t]{4}{*}{ A. bovis } & 165 rRNA & EE1 & TCCTGGCTCAGAACGAACGCTGGCGGC & 55 & $\sim 1430$ & {$[26,27]$} \\
\hline & & EE2 & AGTCACTGACCCAACCTTAAATGGCTG & & & \\
\hline & & $A B 1 f$ & CTCGTAGCTTGCTATGAGAAC & 60 & 551 & \\
\hline & & AB1r & TCTCCCGGACTCCAGTCTG & & & \\
\hline \multirow[t]{2}{*}{ A. marginale } & msp4 & AmargMSP4Fw & CTGAAGGGGGAGTAATGGG & 60 & 344 & {$[28]$} \\
\hline & & AmargMSP4Rev & GGTAATAGCTGCCAGAGATTCC & & & \\
\hline \multirow[t]{2}{*}{ A. ovis } & msp4 & MSP45 & GGGAGCTCCTATGAATTACAGAGAATTGTTTAC & 55 & 869 & {$[29]$} \\
\hline & & MSP43 & CCGGATCCTTAGCTGAACAGAATCTTGC & & & \\
\hline \multirow[t]{6}{*}{ A. capra } & $g l t A$ & Outer-f & GCGATTTTAGAGTGYGGAGATTG & 55 & 1031 & {$[6]$} \\
\hline & & Outer-r & TACAATACCGGAGTAAAAGTCAA & & & \\
\hline & & Inner-f & TCATCTCCTGTTGCACGGTGCCC & 60 & 594 & {$[22]$} \\
\hline & & Inner-r & СTCTGAATGAACATGCCCACCCT & & & \\
\hline & 165 rRNA & Forward & GCAAGTCGAACGGACCAAATCTGT & 58 & 1261 & {$[30]$} \\
\hline & & Reverse & CCACGATTACTAGCGATTCCGACTTC & & & \\
\hline \multirow[t]{2}{*}{ Ehrlichia spp. } & 165 rRNA & ECC & AGAACGAACGCTGGCGGCAAGC & 60 & 450 & {$[26]$} \\
\hline & & $\mathrm{ECB}$ & CGTATTACCGCGGCTGCTGGCA & & & \\
\hline \multirow[t]{2}{*}{ SFG rickettsiae } & OmpA & $\operatorname{Rr} 190.70$ & ATGGCGAATATTTCTCCAAAA & 55 & 632 & {$[31]$} \\
\hline & & $\operatorname{Rr} 190.701$ & GTTCCGTTAATGGCAGCATCT & & & \\
\hline
\end{tabular}

Abbreviation: $T$, temperature

\section{Nucleotide sequence accession numbers}

The representative sequences of the identified pathogens in this study were deposited in the GenBank database and assigned accession numbers as follows: MH085202, MH085203 and MK271372 for 18S rRNA gene sequences of T. capreoli, T. cervi and T. luwenshuni, respectively; MH085195-MH085196 and MK271373-MK271375 for $16 S$ rRNA gene sequences of A. bovis; MH085197 and MH085198 for $16 S$ rRNA gene sequences of $A$. phagocytophilum and A. capra, respectively; MK271379 for the msp4 gene sequence of $A$. ovis; and MH094751 for the $g l t A$ gene sequence of $A$. capra.

\section{Results}

Sixteen (11.9\%) of 134 goats and 5 (55.6\%) of 9 free-ranging C. pygargus tested positive for piroplasms by nested PCR, which amplifies an approximately $430 \mathrm{bp}$ band of the $18 S$ rRNA gene of Theileria/Babesia spp. All amplicons were sequenced, and BLAST analysis revealed that the obtained sequences belonged to three different
Theileria species; Babesia was not identified in any of these amplicon sequences. Sequence analysis revealed that the $18 S$ rRNA sequences detected from goats were $100 \%$ identical to each other and to the isolates GNhl4 (MG799814), SX01 (MG930123) and PZG5 (LC326009) of T. luwenshuni identified in Haemaphysalis longicornis and goats from China and Myanmar. The 18S rRNA sequences of Theileria detected from C. pygargus were classified into two groups. Two $18 S$ rRNA sequences were $100 \%$ identical to the Theileria sp. 3185/02 (GenBank: DQ866842) identified in roe deer (Capreolus capreolus) from Spain and the isolate TCCRO1 of T. capreoli (GenBank: KY359359) identified in grey wolf (Canis lupus) from Croatia [13]. Three sequences were $100 \%$ identical to the isolates Am4 (GenBank: MG041373) and 13WYs1a (GenBank: KP407020) of $T$. cervi isolated from Ixodes persulcatus and sika deer (Cervus nippon) in Russia and China, respectively. To further characterize these three Theileria species, the first-round PCR amplicons from positive samples ( 1410 bp) were 
sequenced. Sequence and phylogenetic analysis revealed that Theileria sp. (PB23-2, GenBank: MK271372) identified from goats was closely related to $T$. luwenshuni identified from sheep and goats (GenBank: KC769996, JX469512, JX469518 and KC854408) in China; Theileria sp. (Pb17c, GenBank: MH085202) identified from $C$. pygargus was clustered together with $T$. capreoli isolates from roe deer (GenBank: AY726011 and DQ866842) in Spain, Reeves' muntjac (GenBank: KJ451470) and whitelipped deer (GenBank: JX134576) in China and sika deer in Japan (GenBank: AB012189); Theileria sp. (Pb22a, GenBank: MH085203) from C. pygargus was closely related to $T$. cervi identified from sika deer in China and Japan (GenBank: HQ184411, KT959224, AB602882, AB602887, AB012196 and AB012199) (Fig. 1).
Four Anaplasma species were detected in goats and C. pygargus, including A. ovis, A. bovis, A. phagocytophilum and A. capra. Anaplasma ovis was detected in 11 (8.2\%) of 134 goats. The msp4 sequences (MK271379) detected in goats were $100 \%$ identical to the A. ovis isolates from sheep (GenBank: MF071307 and AY702924) in China and Italy. Anaplasma bovis infection was found in $6(4.5 \%)$ goats and 7 (77.8\%) C. pygargus. The $16 S$ rRNA sequences (551 bp) amplified from goats and C. pygargus provided five sequence variants that had $98.8-99.8 \%$ identity. These A. bovis variants (Ab27-2, Ab35-1 and Ap45-3 from goats, MK271373-MK271375; Ab18a and Ab21b from C. pygargus, MH085195 and MH085196) were $99.3-100 \%$ identical to the $A$. bovis isolate b2-25a (GenBank: MF066914) from sheep in China. Anaplasma

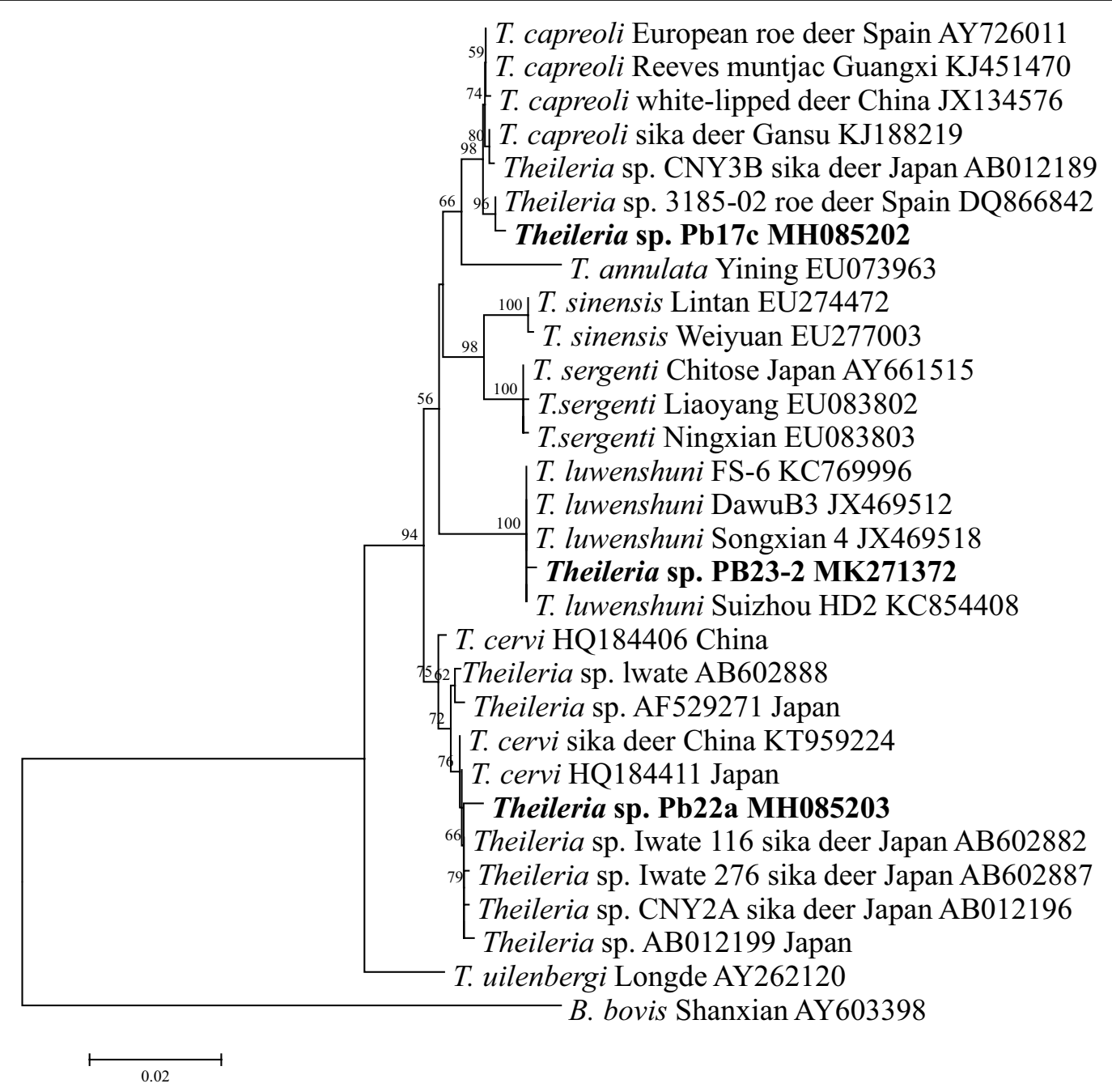

Fig. 1 Phylogenetic analysis of the Theileria species identified in this study based on the 185 rRNA gene. Babesia bovis was used as outgroup. Boldface indicates the sequences obtained in this study. The phylogenetic trees were inferred by using the neighbor-joining (NJ) method with the Kimura two-parameter model, and the bootstrap test was replicated 1000 times. There was a total of 1367 positions in the final dataset 
phagocytophilum was detected in three (33.3\%) C. pygargus. The $16 S$ rRNA sequences of $A$. phagocytophilum (641 bp) obtained from this study (Ap23a, MH085197) were $100 \%$ identical to each other and to isolate ApGOv1 derived from sheep (GenBank: KM285230) in Tunisia, GS29 from cattle (GenBank: GU223365) in Turkey, and Ac30B from sika deer (GenBank: AB588976) in Japan.

Three C. pygargus (33.3\%) were positive for A. capra. These A. capra isolates were molecularly characterized based on $16 S$ rRNA and gltA genes. The $16 S$ rRNA gene sequences (Ac19f, MH085198) were 99.8\% identical to the A. capra isolate S63a identified from sheep (MF066918), Anaplasma sp. Kamoshika17 from Japanese serows (GenBank: AB509223), Anaplasma sp. NS104 from deer (GenBank: AB454075), M141a from H. qinghaiensis ticks (GenBank: KX673825), and 99.7\% identical to the isolate HLJ-14 of $A$. capra (GenBank: KM206273) isolated in humans (GenBank: KM206274). The gltA sequences (Ac19a, MH094751) were 98.5-98.7\% identical to A. capra isolates from sheep and $H$. qinghaiensis ticks (GenBank: MF071308, MF071309, KX685885 and KX685886), but they had a low sequence identity
(87.6\%) to the corresponding sequence of $A$. capra HLJ14 from humans (GenBank: KM206274). Phylogenetic analyses revealed that the isolate identified in C. pygargus was clustered into the A. capra clade based on $16 S$ rRNA gene, distinct from other well-recognized Anaplasma species (Fig. 2). However, based on the gltA gene, the isolate was closely related to $A$. capra strains from sheep and $H$. qinghaiensis, but separated clearly from the human isolate HLJ-14 (Fig. 3).

Co-infection with Anaplasma and Theileria was observed in 2 goats and 5 C. pygargus. Co-infection that involved potential zoonotic organisms (A. phagocytophilum and A. capra) was found in 2 C. pygargus. Moreover, all animals included in this study tested negative for $A$. marginale, Ehrlichia spp. and SFG rickettsiae.

\section{Discussion}

The occurrence of tick-borne pathogens has been well documented in various domestic and wild ruminants in many countries. In addition to their veterinary importance, many tick-borne pathogens are known to have zoonotic potential. In the present study, the presence

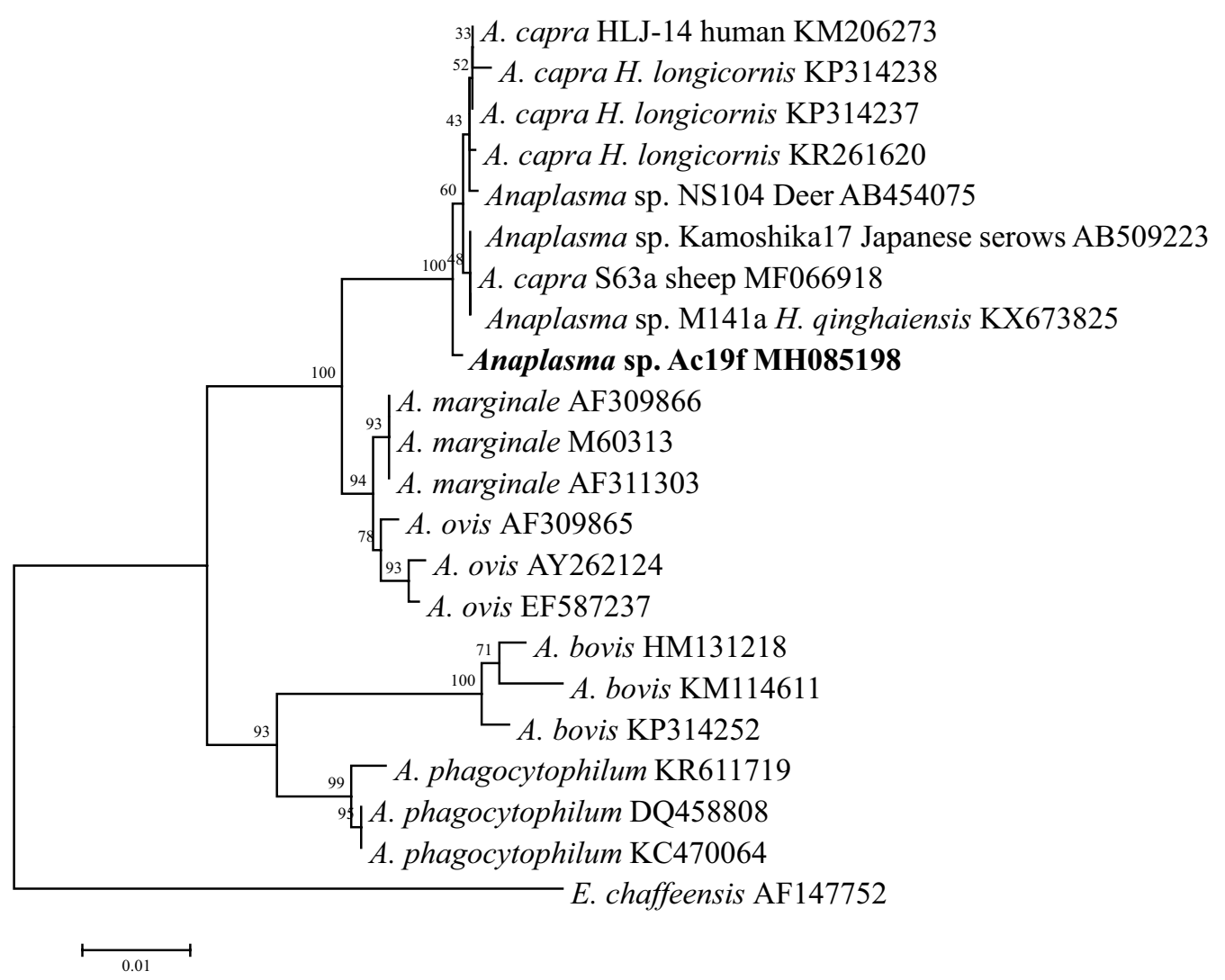

Fig. 2 Phylogenetic analysis of the Anaplasma capra based on the 165 rRNA gene. Ehrlichia chaffeensis was used as outgroup. Boldface indicates the sequences obtained in this study. The phylogenetic trees were inferred by using the neighbor-joining (NJ) method with the Kimura two-parameter model, and the bootstrap test was replicated 1000 times. There was a total of 1219 positions in the final dataset 


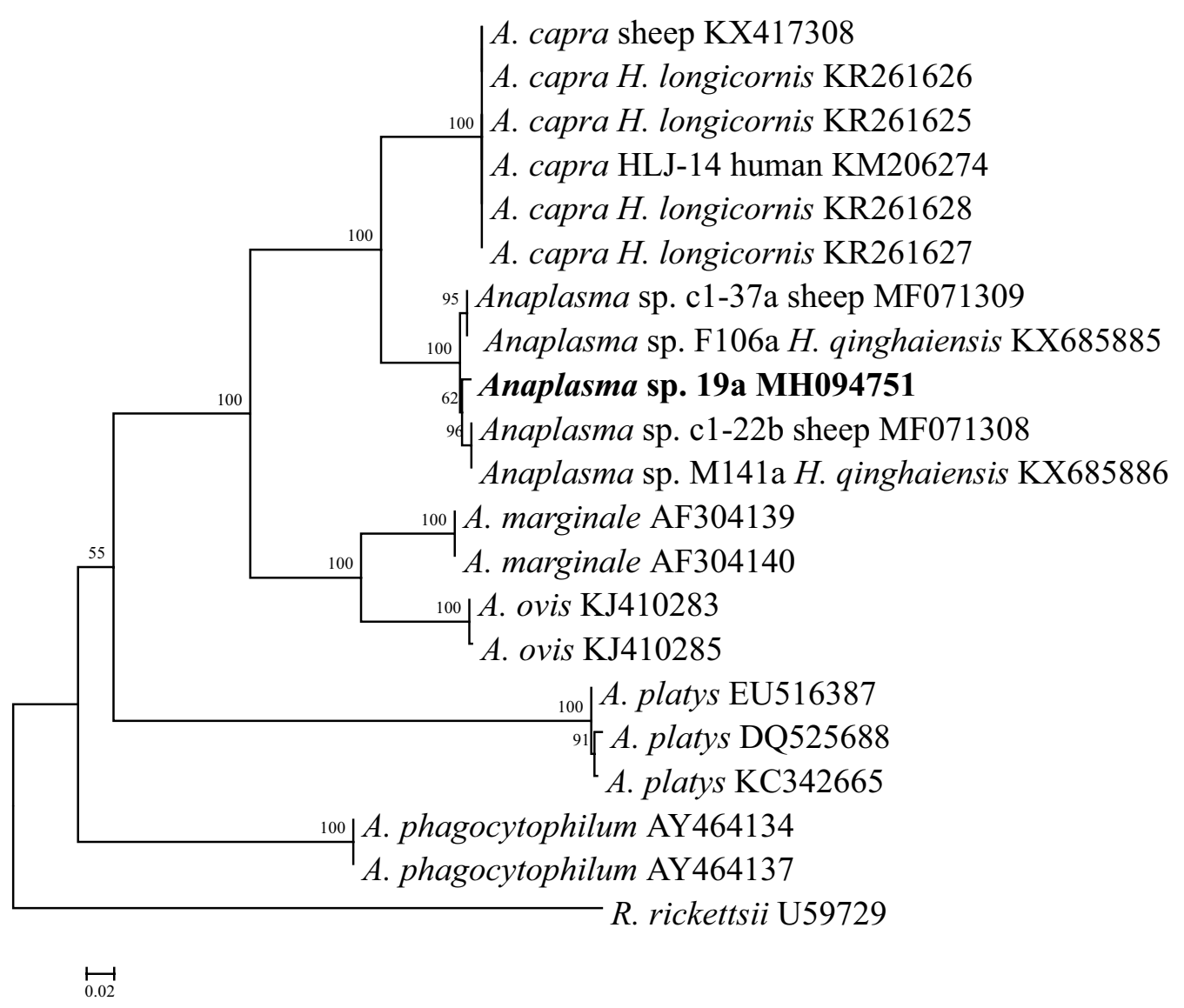

Fig. 3 Phylogenetic analysis of the Anaplasma capra based on the gltA gene. Rickettsia rickettsii was used as outgroup. Boldface indicates the sequences obtained in this study. The phylogenetic trees were inferred by using the neighbor-joining (NJ) method with the Kimura two-parameter model, and the bootstrap test was replicated 1000 times. There was a total of 563 positions in the final dataset

of tick-borne bacteria and protozoans was investigated in domestic and wild small ruminants; three Theileria (T. luwenshuni, T. capreoli and T. cervi) and four Anaplasma species (A. ovis, A. phagocytophilum, A. bovis and $A$. capra) were identified in goats and free-ranging C. pygargus.

Protozoan parasites of the genus Theileria are obligatory intracellular parasites that infect leukocytes and erythrocytes of both wild and domestic animals. Aside from highly pathogenic Theileria species, such as $T$. parva and T. annulata, others are described as low pathogenic [13]. Asymptomatic infections by different Theileria species have so far been identified in a variety of wild and domestic animals [1, 14-17]. In this study, T. luwenshuni was identified in goats, and T. capreoli and T. cervi in C. pygargus in Heilongjiang Province, northeastern China. Theileria luwenshuni is a new Theileria species highly pathogenic for small domestic ruminants (goats and sheep); it is widely distributed in China and causes substantial economic losses for the livestock industry
[18]. Theileria capreoli and T. cervi have been frequently reported in cervid species. Theileria capreoli was first described in roe deer, and recorded subsequently in red deer, fallow deer, roe deer and Chinese water deer [16, 19]. Theileria cervi is a non-pathogenic species that has been reported in brown brocket deer, white-tailed deer, sika deer, axis deer, marsh deer, elk, pampas deer and mule deer $[14,15,20]$. Our findings suggest that $C$. pygargus may serve as a reservoir of T. capreoli and T. cervi in northeastern China.

The genus Anaplasma encompasses a group of obligate intracellular bacteria that are causative agents of anaplasmosis with veterinary and public health significance [5]. They have different cellular tropism, vectors, pathogenicity and host range. In this study, $A$. ovis and $A$. bovis were identified in goats, and A. phagocytophilum and $A$. bovis in free-ranging C. pygargus. Anaplasma ovis, A. phagocytophilum and $A$. bovis are frequently detected tickborne pathogens in small ruminants around the world; however, the infection of $A$. phagocytophilum was not 
found in goats included in this study. Aside from A. ovis, A. phagocytophilum and A. bovis have the broadest host range. Our results suggested that the $C$. pygargus may serve as reservoir hosts for $A$. phagocytophilum and $A$. bovis. Considering the fact that $A$. phagocytophilum and A. bovis can affect a variety of domestic and wild animals, the risk of cross-infection is high in areas where wild and domestic animals share a common habitat.

Apart from those well-known Anaplasma species, a novel Anaplasma species named A. capra has been recently described in goats and identified subsequently as a human pathogen in Heilongjiang Province in northeastern China [6]. The molecular investigations of $A$. capra in small domestic ruminants and several tick species revealed that this pathogen is widely distributed in China, subdivided into two genotypes [11, 21, 22]. In this study, A. capra was identified in C. pygargus in Heilongjiang Province, where the human isolate HLJ-14 was described [6]. Phylogenetic analysis showed that the isolates from $C$. pygargus were closely related to A. capra genotype identified from sheep and $H$. qinghaiensis, but differ with the genotype from human, suggesting the high degree of genetic diversity of this agent. Moreover, since $16 S$ rRNA sequences of $A$. capra have been previously detected in Japanese serows (AB509223) and deer (Anaplasma sp. NS104, AB454075) from Japan [23], the finding of this agent in C. pygargus was not surprising. These findings, together with previous reports, suggest that $A$. capra could be efficiently maintained in nature through enzootic cycles between ticks and wild cervids, and the A. capra genotype identified in C. pygargus is distinct from the human genotype.

In summary, several tick-borne pathogens were identified in small domestic and wild ruminants from northeastern China; three (T. luwenshuni, A. ovis and A. bovis) were identified in goats and five (T. capreoli, T. cervi, A. phagocytophilum, A. bovis and A. capra) in free-ranging C. pygargus. These findings suggest a greater diversity of tick-borne pathogens in wild animals than that in domestic animals. Furthermore, the infection of $A$. marginale, Ehrlichia spp. and SFG rickettsiae was not found in those animals included this study. Goats and C. pygargus serve as reservoirs for tick-borne protozoans and bacteria with a broad host range, such as A. phagocytophilum, A. bovis and $A$. capra, posing a potential threat to domestic and other wild animals as well as humans.

\section{Conclusions}

This study describes the occurrence of tick-borne bacteria and protozoans in goats and C. pygargus from northeastern China. Three Theileria (T. luwenshuni, T. capreoli and T. cervi) and four Anaplasma species (A. ovis, A. phagocytophilum, $A$. bovis and $A$. capra) with veterinary and medical significance were identified in small domestic and wild ruminants. The identification of these causative agents in domestic and wild animals provides useful information for the control and management of tick-borne diseases.

\section{Abbreviations}

PCR: polymerase chain reaction; DNA: deoxyribonucleic acid; gltA: the citrate synthase gene; msp: major surface protein; UV: ultraviolet.

\section{Acknowledgements}

Not applicable.

\section{Authors' contributions}

$X W$ and $J Y$ designed this study and critically revised the manuscript. HW and JY participated in sample collection and DNA preparation. HW, JY, UM, ZL and $\mathrm{MZ}$ performed the experiments, data analysis, and drafted the manuscript. All authors read and approved the final manuscript.

\section{Funding}

This study was financially supported by the National Project for Prevention and Control of Transboundary Animal Diseases (Grant No. 2017YFD0501800), the National Key R\&D Program for the 13th Five-Year Plan, the Ministry of Science and Technology, China.

\section{Availability of data and materials}

Sequences have been submitted in the GenBank database under the following Accession Numbers: MH085202, MH085203 and MK271372 for $18 \mathrm{~S}$ rRNA gene sequences of T. capreoli, T. cervi and T. luwenshuni, respectively; MH085195-MH085196 and MK271373-MK271375 for 165 rRNA gene sequences of A. bovis; MH085197 and MH085198 for 16S rRNA gene sequences of A. phagocytophilum and A. capra, respectively; MK271379 for the msp4 gene sequence of A. ovis; and MH094751 for the gltA gene sequence of A. capra.

\section{Ethics approval and consent to participate}

Animal treatment and sample preparation complied with the Animal Ethics Procedures and Guidelines and was approved by the Animal Ethics Committee of Northeast Forestry University.

\section{Consent for publication}

Not applicable.

\section{Competing interests}

The authors declare that they have no competing interests.

\section{Author details}

${ }^{1}$ College of Wildlife Resource, Northeast Forestry University, Harbin 150040 , Heilongjiang, People's Republic of China. ${ }^{2}$ State Key Laboratory of Veterinary Etiological Biology, Key Laboratory of Veterinary Parasitology of Gansu Province, Lanzhou Veterinary Research Institute, Chinese Academy of Agricultural Sciences, Xujiaping 1, Lanzhou 730046, Gansu, People's Republic of China. ${ }^{3}$ Center of Conservation Medicine \& Ecological Safety, Northeast Forestry University, Harbin 150040, Heilongjiang, People's Republic of China.

Received: 17 December 2018 Accepted: 5 June 2019

Published online: 13 June 2019

References

1. Pereira A, Parreira R, Nunes M, Casadinho A, Vieira ML, Campino L, Maia C. Molecular detection of tick-borne bacteria and protozoa in cervids and wild boars from Portugal. Parasit Vectors. 2016;9:251.

2. Ghai RR, Mutinda M, Ezenwa VO. Limited sharing of tick-borne hemoparasites between sympatric wild and domestic ungulates. Vet Parasitol. 2016;226:167-73 
3. Kauffmann M, Rehbein S, Hamel D, Lutz W, Heddergott M, Pfister K, Silaghi C. Anaplasma phagocytophilum and Babesia spp. in roe deer (Capreolus capreolus), fallow deer (Dama dama) and mouflon (Ovis musimon) in Germany. Mol Cell Probe. 2017;31:46-54.

4. Cezanne R, Mrowietz N, Eigner B, Duscher GG, Glawischnig W, Fuehrer HP. Molecular analysis of Anaplasma phagocytophilum and Babesia divergens in red deer (Cervus elaphus) in Western Austria. Mol Cell Probe. 2017;31:55-8.

5. Rar V, Golovljova I. Anaplasma, Ehrlichia, and "Candidatus Neoehrlichia" bacteria: pathogenicity, biodiversity, and molecular genetic characteristics, a review. Infect Genet Evol. 2011;11:1842-61.

6. Li H, Zheng YC, Ma L, Jia N, Jiang BG, Jiang RR, et al. Human infection with a novel tick-borne Anaplasma species in China: a surveillance study. Lancet Infect Dis. 2015;15:663-70.

7. Gimenez C, Casado N, Criado-Fornelio A, de Miguel FA, DominguezPenafiel G. A molecular survey of Piroplasmida and Hepatozoon isolated from domestic and wild animals in Burgos (northern Spain). Vet Parasitol. 2009:162:147-50.

8. Liu JL, Yang JF, Guan GQ, Liu AH, Wang BJ, Luo JX, Yin H. Molecular detection and identification of piroplasms in sika deer (Cervus nippon) from Jilin Province, China. Parasit Vectors. 2016;9:156.

9. Li YQ, Chen Z, Liu ZJ, Liu JL, Yang JF, Li Q, et al. Molecular identification of Theileria parasites of northwestern Chinese Cervidae. Parasit Vectors. 2014;7:225.

10. Zhao W, Wang JG, Yang ZY, Liu AQ. Dominance of the Enterocytozoon bieneusi genotype BEB6 in red deer (Cervus elaphus) and Siberian roe deer (Capreolus pygargus) in China and a brief literature review. Parasite. 2017;24:54

11. Yang JF, Liu ZJ, Niu QL, Liu JL, Han R, Guan GQ, et al. A novel zoonotic Anaplasma species is prevalent in small ruminants: potential public health implications. Parasit Vectors. 2017:10:264.

12. Tamura K, Dudley J, Nei M, Kumar S. MEGA4: molecular evolutionary genetics analysis (MEGA) software version 4.0. Mol Biol Evol. 2007;24:1596-9.

13. Garcia-Sanmartin J, Aurtenetxe O, Barral M, Marco I, Lavin S, Garcia-Perez AL, Hurtado A. Molecular detection and characterization of piroplasms infecting cervids and chamois in northern Spain. Parasitology. 2007:134:391-8.

14. Silveira JAG, Rabelo EML, Lacerda ACR, Borges PAL, Tomas WM, Pellegrin $\mathrm{AO}$, et al. Molecular detection and identification of hemoparasites in pampas deer (Ozotoceros bezoarticus Linnaeus, 1758) from the Pantanal Brazil. Ticks Tick Borne Dis. 2013:4:341-5.

15. da Silveira JAG, Rabelo EML, Ribeiro MFB. Detection of Theileria and Babesia in brown brocket deer (Mazama gouazoubira) and marsh deer (Blastocerus dichotomus) in the State of Minas Gerais, Brazil. Vet Parasitol. 2011;177:61-6.

16. Han Jl, Jang HJ, Lee SJ, Na KJ. High prevalence of Theileria sp. in wild Chinese water deer (Hydropotes inermis argyropus) in South Korea. Vet Parasitol. 2009;164:311-4.

17. Fuehrer HP, Biro N, Harl J, Worliczek HL, Beiglbock C, Farkas R, Joachim A, Duscher GG. Molecular detection of Theileria sp ZS TO4 in red deer (Cervus elaphus) and questing Haemaphysalis concinna ticks in Eastern Austria. Vet Parasitol. 2013:197:653-7.
18. Yin H, Liu Z Guan G,Liu A, Ma M Ren Q Luo J. Detection and differentiation of Theileria luwenshuni and T. uilenbergi infection in small ruminants by PCR. Transbound Emerg Dis. 2008:55:233-7.

19. Hornok S, Sugar L, Horvath G, Kovacs T, Micsutka A, Gonczi E, et al. Evidence for host specificity of Theileria capreoli genotypes in cervids. Parasit Vectors. 2017;10:473.

20. Inokuma H, Tsuji M, Kim SJ, Fujimoto T, Nagata M, Hosoi E, et al. Phylogenetic analysis of Theileria sp. from sika deer, Cervus nippon, in Japan. Vet Parasitol. 2004:120:339-45.

21. Sun XF, Zhao L, Wen HL, Luo LM, Yu XJ. Anaplasma species in China. Lancet Infect Dis. 2015;15:1263-4

22. Yang J, Liu Z, Niu Q, Liu J, Han R, Liu G, et al. Molecular survey and characterization of a novel Anaplasma species closely related to Anaplasma capra in ticks, northwestern China. Parasit Vectors. 2016;9:603.

23. Sato M, Nishizawa I, Fujihara M, Nishimura T, Matsubara K, Harasawa R. Phylogenetic analysis of the 16S rRNA gene of Anaplasma species detected from Japanese serows (Capricornis crispus). J Vet Med Sci. 2009:71:1677-9.

24. Olmeda AS, Armstrong PM, Rosenthal BM, Valladares B, del Castillo A, de Armas F, et al. A subtropical case of human babesiosis. Acta Trop. 1997:67:229-34.

25. Yang JF, Li YQ, Liu ZJ, Liu JL, Guan GQ, Chen Z, et al. Molecular evidence for piroplasms in wild Reeves' muntjac (Muntiacus reevesi) in China. Parasitol Int. 2014;63:713-6.

26. Barlough JE, Madigan JE, DeRock E, Bigornia L. Nested polymerase chain reaction for detection of Ehrlichia equi genomic DNA in horses and ticks (Ixodes pacificus). Vet Parasitol. 1996;63:319-29.

27. Kawahara M, Rikihisa Y, Lin Q, Isogai E, Tahara K, Itagaki A, et al. Novel genetic variants of Anaplasma phagocytophilum, Anaplasma bovis, Anaplasma centrale, and a novel Ehrlichia sp. in wild deer and ticks on two major islands in Japan. Appl Environ Microbiol. 2006;72:1102-9.

28. Torina A, Agnone A, Blanda V, Alongi A, D'Agostino R, Caracappa S, et al. Development and validation of two PCR tests for the detection of and differentiation between Anaplasma ovis and Anaplasma marginale. Ticks Tick Borne Dis. 2012;3:282-6.

29. de la Fuente J, Atkinson MW, Naranjo V, de Mera IGF, Mangold AJ, Keating KA, Kocan KM. Sequence analysis of the msp4 gene of Anaplasma ovis strains. Vet Microbiol. 2007:119:375-81.

30. Yang Y, Yang ZP, Kelly P, Li J, Ren YJ, Wang CM. Anaplasma phagocytophilum in the highly endangered Pere David's deer Elaphurus davidianus. Parasit Vectors. 2018;11:25.

31. Roux V, Fournier PE, Raoult D. Differentiation of spotted fever group rickettsiae by sequencing and analysis of restriction fragment length polymorphism of PCR-amplified DNA of the gene encoding the protein rOmpA. J Clin Microbiol. 1996;34:2058-65.

\section{Publisher's Note}

Springer Nature remains neutral with regard to jurisdictional claims in published maps and institutional affiliations.

Ready to submit your research? Choose BMC and benefit from

- fast, convenient online submission

- thorough peer review by experienced researchers in your field

- rapid publication on acceptance

- support for research data, including large and complex data types

- gold Open Access which fosters wider collaboration and increased citations

- maximum visibility for your research: over 100M website views per year

At $B M C$, research is always in progress.

Learn more biomedcentral.com/submissions 